\title{
The Reality of Risk Management in Private Jordanian Universities from the Viewpoint of Faculty Members
}

\author{
Reda S.M. Al Mawadieh ${ }^{1}$, Mohammed Al-Badawi² \& Khaled Al-Sarairah ${ }^{3}$ \\ ${ }^{1}$ Faculty of Education - Zarqa Private University, Jordan \\ ${ }^{2}$ Faculty of Arts - Zarqa Private University, Jordan \\ ${ }^{3}$ Faculty of Education - Muatah University, Jordan \\ Correspondence: Reda S.M. Al Mawadieh, Dean of faculty of education at Zarqa Private University, Jordan.
}

Received: June 26, 2020

doi:10.5430/ijhe.v9n5p274
Accepted: August 4, 2020

Online Published: August 5, 2020

URL: https://doi.org/10.5430/ijhe.v9n5p274

\begin{abstract}
This study aimed at investigating the reality of risk management in private Jordanian universities from the viewpoint of faculty members. In order to achieve the study objectives, the descriptive analytical approach was adopted. A questionnaire was developed for the purpose of collecting data from (106) subjects that were randomly selected from three private Jordanian universities (Aqaba University of Technology, Zarqa University, and the University of the Middle East). The results of the study indicated that the mean of the reality of risk management practice in private Jordanian universities from the viewpoint of the faculty members was medium. It was also revealed that there are no statistically significant differences at the level of significance $(\alpha \leq 0.05)$ in the reality of risks management practice in Jordanian universities especially from the point of view of the teaching staff members due to variables (sex, academic experience, academic rank, and the type of college). The study recommended holding training courses for workers in private Jordanian universities on planning for risk management.
\end{abstract}

Keywords: risk management, private Jordanian universities, faculty members

\section{Introduction}

Higher education is the basis for the development and progress of society's institutions. Universities are considered as beacons of change and development in building societies. The management of higher education is a well-planned process that seeks to achieve the targeted goals and results. In addition, the higher education system is the backbone for the rest of society's systems. Of course, this can only be sought through an effective management which is capable of sound planning, diagnosing its weaknesses and strengths, and the ability to overcome all the problems and challenges it faces.

Thus, the university's administration is responsible for the continuous planning that would enable the university to achieve its goals. The role of the administration lies also in arriving at the best ways to bring about the required development in various aspects of the educational process and improving its outputs. The importance of university management increases as a result of the challenges and risks facing various educational institutions, whether at the level of general education, or higher education which constitutes a danger to the progress of these institutions.

Planning is characterized as an accurate, comprehensive, and continuous process which includes the threats, risks and opportunities faced by the university, as well as how to manage and deal with them. This involves, striving to find appropriate alternatives, objectives, policies, strategies, executive plans, and continuously monitoring their implementation. Universities management must continuously think strategically with the many changes, risks and threats that may occur during their operations, which may influence their effectiveness of risk management (Muzaffar, 2016.)

Risks are considered to be an important part of the life of every institution, regardless of their shape, size, or nature of work. So, all educational institutions have to be preparedin order to face them, and they should have the conscious leaderships that would contribute to the protection of the educational institutions, including schools. It is necessary to introduce the concept of risk management (Ali, 2016). It is seen as a qualitative skill whose creation and development requires training and continuous application of managers. In addition to the ability to predict an event before it occurs (Adam \&Kritsonis, 2012) the risk management process is defined as an informed and rational 
management that contributes to the protection of the institution, to the improvement of its performance, and also to the solving of the problems that may occur in the future and address them (Megginson, Bortolotti, D'souza, and Fantini, 2000).

Risk management is of great importance in higher education institutions, sincethese institutions have witnessed significant expansion and increase in the numbers of students, workers, faculty-members and various facilities. Such expansion hasdictated the necessity of benefiting from risk management and its role in providing protection for these institutions and pushing them to continue within their performance and activity efficiently and effectively (Al-Anazi and Al-Dulaimi, 2015). So, risk management includes determining tasks and responsibilities as well as providing operational framework for the institution to support and implement future activities in a coordinated and controlled manner. It also involves developing decision-making, planning and prioritization methods through common awareness of the organization's activities, and awareness of the negative and positive changes as well as opportunities available. In addition, it requires effective management, use and allocation of capital and the available resources (Al-Najjar, 2017).

The importance of risk management in universities emerges from its constant endeavor to reduce waste and resources. The occurrence of risks might consume these available resources, and reduce the negative effects of the state of uncertainty. Working to reduce the possibility of a risk might reduce the potential losses caused by that risk. Planning for risks provide confidence, security and stability in the university, and helps it to progress in an organized manner.

\subsection{Objectives of the Study}

This study seeks to achieve the following objectives:

1. Knowing the reality of risk management practice in private Jordanian universities from the viewpoint of their faculty members.

2. Detecting the differences in the reality of risk management practice in private Jordanian universities from the viewpoint of the faculty members according to the variables (gender, academic experience, academic rank, and type of college).

\subsection{The Significance of the Study}

The significance of this study lies in its endeavor to uncover the reality of planning for risk management in private Jordanian universities in two ways:

The scientific significance: This study is one of the few recent studies in the subject of risk management in Jordanian universities, and thus it enriches the Arabic literature in this specific area of research. It also opens new horizons for researchers to address this topic from various aspects, with the aim of reaching studies that can contribute to supporting theoretical literature in general.

Practical significance: This study may be useful to reveal the importance of maintaining a university environment that is characterized by the lowest possible risks. It may also contribute to finding ways to manage risks of all kinds for people working in universities administration, decision-makers at the Ministry of Higher Education and Scientific Research, the Accreditation Commission for Higher Education Institutions, quality assurance, researchers, and graduate students in the field of risk management.

\subsection{Terms of the Study}

Risk Management: Minimizing the negative effects of risks to the lowest possible level with the least possible cost. This can be achieved by identifying, measuring and controlling the risk (Abdel-Al, 2007, 44)

Faculty members: They are the people who teach in higher education institutions such as: universities and university colleges who hold a $\mathrm{PhD}$ in one of the fields of knowledge, and occupy one of the following academic ranks: professor, associate professor, and assistant professor.

\subsection{Study Boundaries}

The study was limited to the faculty members in private Jordanian universities represented by the following: (Aqaba University of Technology, Middle East University, and Zarqa University), which were applied during the second semester 2019/2020. The results of this study were determined by the responses provided by the subjects of the study to the questionnaire clauses that were prepared for this purpose. The information was collected using the psychometric properties of the study instrument. 


\section{Review of Related Literature}

This section deals with some of the previous studies that tackled risk management in education. These studies are presented in chronological order. Helsloot\& Jong (2006) analyzed and studied risks in higher education and scientific research based on three areas. The practical benefit of this division is first; to make it easier to see the risks that are unique to higher education (knowledge care).Second, what risks depend on developments in society (a microscopic projection of society); and third what risks are similar to those faced by any other institution i.e. education as an institution. The data of the study was collected using questionnaires, meetings and interviews. The study revealed a number of results; the most important of which was that higher education institutions still lacked an integrated policy on safety, security and crisis management within individual institutions. Moreover, there is little communication between the institutions, employees, and students, and awareness is limited to a range of risks to which they are exposed in their environment. At the same time, institutions do not tend to share their experiences in this field with others. Even within individual institutions, there is often little staff and student participation in safety and security policy and its implementation.

Furthermore, Al-Zubaidi (2014) conducted a study that aimed at identifying the level of risk management among the deans of the private university colleges in the governorate of Baghdad from the viewpoint of heads of departments and faculty members. In order to achieve the research objectives, the analytical descriptive approach was adopted. Eightyeight department heads representing $80 \%$ of the total community of study population, and 535 teachers representing $50 \%$ of the total community of faculty members were selected.

Furthermore, a questionnaire was constructed to identify risk management in the university's private colleges in Baghdad Governorate from the viewpoint of department heads and teaching staff. The questionnaire included four areas: (professional ethics, student fanaticism, the administrative aspect, and study wages) for risk management, and the tool's validity and stability were confirmed. The results also revealed that the deans of the private university in Baghdad governorate rely on risk management plans provided from the viewpoints of department heads and faculty members.

The Booker (2014, Booker) study aimed at exploring the ways to respond effectively to crises, disasters and risks, whether man-made, such as attacks on the university campus, university buildings, or natural risks such as fire, earthquakes, etc. The data of the study was collected using the survey descriptive approach where a questionnaire was prepared, and the validity and stability of the study tool were confirmed. The results of the study indicated that the importance of learning, planning, training and implementation to respond to the crisis and danger situation, as well as the importance of continuous learning of the strategies of the crisis and taking advantage of previous crises are very important criteria in determining risk management.

As for the study of Yarullin et al. (2016), it aimed at defining conditions and achieving the concept of "risks" in the modern educational environment to formulate organizational and methodological conditions for effective risk management of educational projects. The study used the organization approach, which allows viewing the problem as a complete system that is necessary for effective risk management of educational projects. The study defined the conditions that examine the phenomenon of "risk" in the modern educational environment. It also formulated the basic contradiction in studying the risks of educational projects and offered theorganizational and methodological conditions for effective risk management in educational projects. These are set to create more efficient models and practices for risk management in the educational project. The study revealed that there is a continuous increase in the number of high-risk projects in the field of education, as the society uses up more and more manpower and resources necessary to create and maintain government operable elements in the educational environment.

Al-Amri (2018) aimed at adapting and developing the Adapt and Development Scale of Corporate Governance prepared by Credit Lyonnais Securities Asia CLS, as a measure of the governance of Arab universities. The study concluded that the integrity checks ensure integrity and ensure honesty for all workers in the organization. It also reduces deviations, especially those that pose a threat to the interests of stakeholders, and regulates the existing relationships between the executive organization's management and its board of directors and its audit committee. This in turn leads to a reduction in the risks facing the organization and works to raise its performance. Therefore, governance becomes the appropriate tool to protect the organization from risks.

Finally, Al-Mukhlafi (2019) aimed at identifying the degree of application of government school leaders in the Qassim region (Saudi Arabia) to risk management. In order to achieve this, the survey descriptive approach was adopted and the study sample consisted of 456 leaders, a questionnaire was prepared which was verified for its stability and validity as a study tool. The results of the study indicated that the degree of application of school leaders to risk management came with a medium degree. It also showed that there are statistically significant differences 
between estimates of school leaders in the application of risk management, according to the variable of experience, and for the benefit of school leaders with less than 10 years experience, and according to the variable of the educational qualification and for the benefit of school leaders with qualifications (Higher diploma).

\section{Comment on Previous Studies}

Through a survey of previous studies, we can see that there is scarcity of studies that deal with risk management in universities in general and intheArab and Jordanian universities in particular. It can also be noticed that some studies agreed with the current study, and others differed.

In terms of the goal, the study (Helsloot\& Jong, 2006) aimed to analyze and study the risks in higher education and scientific research.The study of Al-Zubaidi (2014) aimed to identify the level of risk management among the deans of the private colleges of the University of Baghdad from the viewpoint of department heads and teachers; while the study of Booker (2014) aimed to discover ways to respond effectively to crises, disasters and risks. The Ameri study (2018) aimed to adapt and develop a measure of the governance of Arab universities to reduce risks in them. However, the current study aims to know the reality of risk management in private Jordanian universities from the viewpoint of their faculty members.

In terms of the approach, the current study that adopted the descriptive survey method was similar to some previous studies such as the study of Hillsloot\& Jong (2006), and Al-Zubaidi (2014) the descriptive analytical approach, and Booker (2014, Booker) the survey descriptive approach.

In terms of the tool used to collect the data, the present study used the questionnaire and was similar to most of the previous studies, including the study of Al-Zubaidi (2014) and Booker (2014). However, Helsloot\& Jong study (2006) relied on the use of interviews and questionnaires as tools for data collection.

\section{Methodology}

This study adopts the descriptive analytical approach as the appropriate approach for the nature of the study. (Melhem, 2017).

\subsection{Study Population and Sample}

The study population consisted of 530 faculty members i.e. all faculty members in the following private Jordanian universities (Aqaba University of Technology in the Southern Region, the University of the Middle East in the Central Region, and Zarqa University in the Northern region) for the second semester of the academic year 2019/2020. The study sample consisted of 106 faculty members who were randomly selected, at a rate of $20 \%$ of the total number of participants.

Table 1. Distribution of study sample individuals according to gender, experience, and academic and college ranks

\begin{tabular}{llll}
\hline Variable & Variable category & Number & Percentage \% \\
\hline Sex & Male & 93 & $88.6 \%$ \\
& Female & 12 & $11.4 \%$ \\
Experience & Total & 105 & $100.0 \%$ \\
& Less than 5 years & 30 & $8.6 \%$ \\
& From 5-10 & 37 & $35.2 \%$ \\
Academic Rank & More than 10 & 38 & $36.2 \%$ \\
& Total & 105 & $100.0 \%$ \\
& Assistant Professor & 67 & $63.8 \%$ \\
Faculty & Associate Professor & 20 & $19.0 \%$ \\
& Professor & 18 & $17.1 \%$ \\
& Total & 105 & $100.0 \%$ \\
& Scientific & 35 & $33.3 \%$ \\
& Humanities & 70 & $66.7 \%$ \\
& Total & 105 & $\% 100.0$ \\
\hline
\end{tabular}




\subsection{The Study Tool}

A 30-item questionnaire was prepared to collect data to know the reality of risk management in private Jordanian universities from the viewpoint of faculty members, by referring to theoretical literature and previous studies. A five-step Likert scale was adopted, based on the domain length equation and consequently the levels are; low (12.33), medium (2.33-3.66), and high (above 3.66).

\subsection{Validity of the Study Tool}

In order to verify the validity of the tool, it was presented in its primary form to 10 specialized referees in educational administration, and they were asked to express an opinion on the clarity of the tool's items and degree of relevance to the study categories. They were also asked to express an opinion about whether the tool is suitable to measure the viewpoint of faculty members about the reality of risk management in private Jordanian universities. In light of the opinions provided by the referees, the wording of some items was modified as $80 \%$ of the referees agreed to their amendments, so the questionnaire in its final form consisted of 30 items.

\subsection{Stability of the Study Tool}

To verify the stability of the study tool the Cronbach Alpha factor was used, at the level of each category, and for the tool as a whole. Table (2) shows the results as follows:

Table 2 . coefficients of study stability

\begin{tabular}{ll}
\hline categories & Cronbach Alpha factor \\
\hline Awareness of risk nature & 0.87 \\
Facing risk & 0.90 \\
Diagnosing risk & 0.86 \\
Taking decisions about risk & 0.88 \\
"risk assessment and review" & 0.92 \\
total & 0.94
\end{tabular}

Table 2 shows that the stability coefficients for the instrument fields and for the instrument as a whole were high. Thus, they were at the overall level (0.94), but at the level of the fields ranged between (0.92-0.66), and these values are acceptable for the purposes of the present study.

\subsection{Quantitative Analysis}

To answer the study questions, the quantitative statistical treatments were performed using the Social Sciences Statistical Package (SPSS), as follows:

1. To answer the first question, "mathematical average, standard deviations, rank and level were extracted.

2. To answer the second question: Multiple Anova was performed.

3. To verify the stability of the study instrument, the Cronbach alpha was used. 4 . To describe the characteristics of the study sample, iterations and percentages were extracted.

\section{Results and Discussion}

This part includes presenting the results and discussing them in light of the questions raised, as well as discussing the results of the study and the recommendations emanating from these results, which are as follows:

First: Presentation of the study results:

In order to answer the first question, which is: "What is the reality of risk management practice in private Jordanian universities from the viewpoint of their faculty members?" arithmetic averages and standard deviations for the responses of the members of the study sample were extracted from faculty members in private universities on the study tool, as is shown in Table (3). 
Table 3. eighted mathematical averages and standard deviations for the reality of risk management practice in private Jordanian universities from the viewpoint of faculty members in descending order

\begin{tabular}{lllll}
\hline Categories & Rank & Mean & Standard deviation & level \\
\hline $\begin{array}{l}\text { Taking decisions } \\
\text { about risk }\end{array}$ & 1 & 3.80 & 0.65 & High \\
$\begin{array}{l}\text { Diagnosing risk } \\
\text { "risk assessment and }\end{array}$ & 2 & 3.75 & 0.72 & High \\
$\begin{array}{l}\text { review" } \\
\text { Facing risk }\end{array}$ & 4 & 3.63 & 0.76 & Medium \\
$\begin{array}{l}\text { Awareness of risk } \\
\text { nature }\end{array}$ & 5 & 1.50 & & Low \\
total & - & 1.40 & 0.33 & Low \\
\hline
\end{tabular}

It is clear from Table 3 that the arithmetic averages of the reality of risk management practice in private Jordanian universities from the viewpoint of faculty members came at the macro level with medium degree, a mean of (2.81), a standard deviation of (0.45). The other domains showed different resultswhere the domainof "taking a decision about therisk "ranked first with an average mean (3.80) and a standard deviation of (0.65).

The second domain was "diagnosing risk" with a mean score of (3.75) and a standard deviation (0.72). The domain of "risk assessment and review" came in third place with a mean score of 3.63 and a standard deviation of (0.76). The fourth place was the domain of "facing risk" with a mean score of (1.50) and a standard deviation of (0.33), and in the fifth and last rank, the domain of "awareness of risk nature" came with amean score of (1.40) and a standard deviation of (0.27).

Moreover, figure 1 shows the variation in the reality of risk management practice in private Jordanian universities according to the categories.

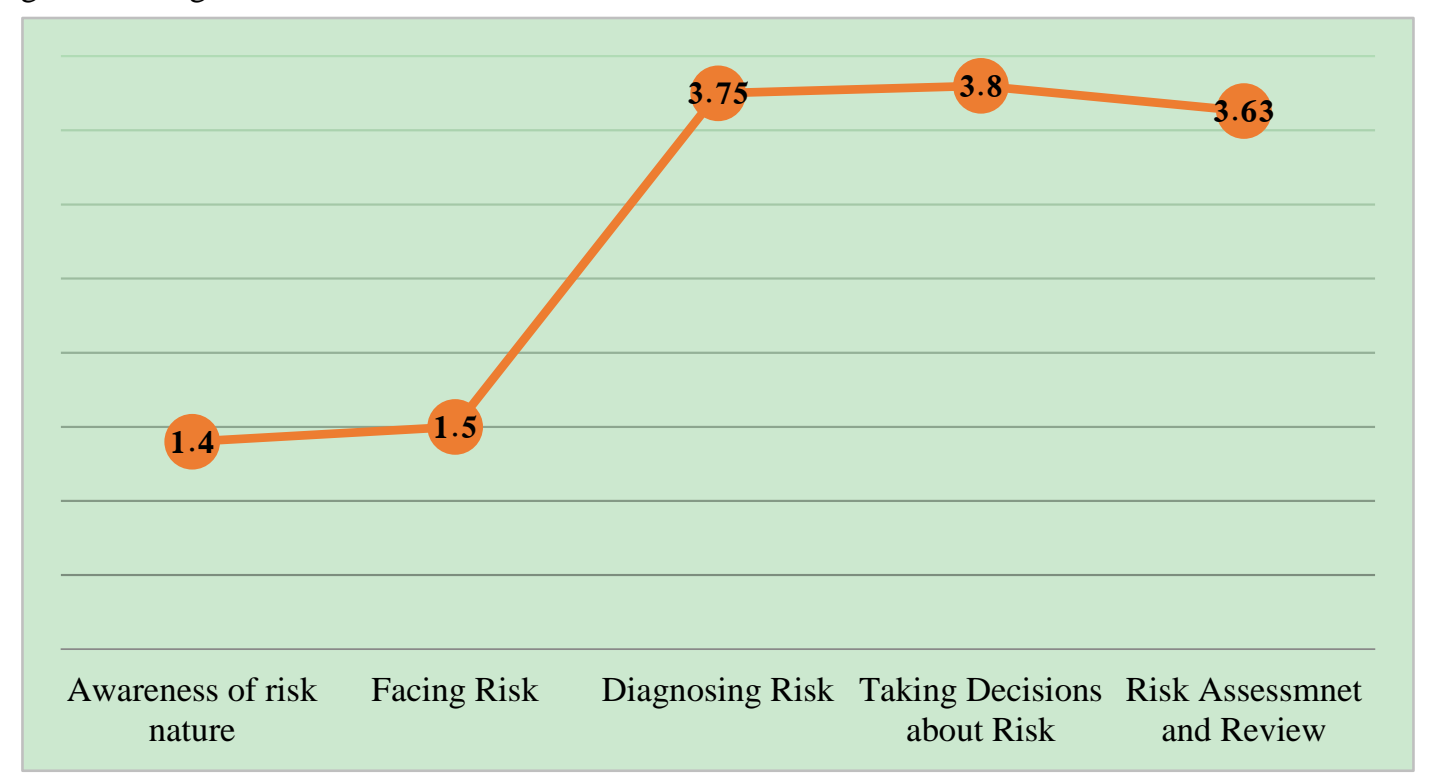

Figure 1. Variation in the reality of risk management practice in private Jordanian universities according to the categories.

The variation in the reality of risk management practice in private Jordanian universities according to the fields

The observation that the domain of decision-making to face the risks came at a high degree can be attributed to the fact that the academic leadership at private universities take many decisions in their work; and that some of these decisions are taken in an uncertain manner so this domain came at a high level. It might also be due to the training programs held by most Jordanian private universities at the beginning of each semester in order to provide them with the skills and competencies of decision-making in light of the risk. The administrative leadership work to analyze the risks and describe them accurately. It also aims to explore the impact of these risks on the university's various 
functions and activities, through a clear strategy for risk management that takes into account the available alternatives to confront the risks. Thus, risk management takes its decisions in cooperation and partnership between all levels in the university. This is consistent with the study of Al-Zubaidi(2014).

The result of the risk diagnosis domain is also attributed to the fact that the risk management follows scientific methods to predict the dangers to which the university may be exposed. Therefore, it conducts training and organizes workshops to develop the leaders 'ability to diagnose potential risks, and determine the probability of occurrence and the degree of their severity. This is normally achieved by conducting studies that enable them to diagnose the risks, anticipate their results and the size of the loss if they occur, in addition topreparing the necessary reports and submitting them to the concerned authorities. This is consistent with Booker (2014, Booker).

The result of risk assessment and review domain is also attributed to the fact that risk management makes sure of the safety of the procedures that are followed to achieve the required results. Reports that clarify deviations from the risk response plan are also prepared under this domain (Booker, 2014).

Moreover, the outcome of facing the risk domain can be attributed to the fact that the university, through the risk management, creates qualified teams capable of facing the risks that the university is exposed to in order to manage the risks within the financial resources of the university. This all exists within the plans and files, butit does not exist on real grounds. The real result and the result may be attributed to the fact that this confrontation was not subject to experience under real-life conditions, and was not practiced under similar circumstances. So, it came with a low degree. This is consistent with the study of Helsloot\& Jong (2006).

The result of the awareness of the nature of the risk is attributed to the fact that risks are not discussed within the internal or external work environment in the university. Thus, it does not constitute a source of risk, and the university's work is not exposed to risks characterized by a high degree of risk, and this may be due to the fact that the academic leaders in the university are fully aware of the nature of the risks the university may be exposed to. Therefore, in risk management, it addresses any potential risk with plans and scenarios for its direction, which is consistent with the Helsloot\& Jong study (2006).

To answer the second research question; are there statistically significant differences at the level of $(0.05 \geq)$ in the reality of risk management practice in private Jordanian universities from the viewpoint of faculty members attributed to the variables (gender, academic experience, academic rank, and type of college)? To answer this question, A Multiple Anova analysis was used.

This is explained in table 4 below:

Table 4. The results of multiple variance analysis to reveal the differences in the reality of risk management practice in private Jordanian universities according to the study variables

\begin{tabular}{|c|c|c|c|c|c|c|c|}
\hline $\begin{array}{l}\text { Dimensions } \\
\text { of the scale }\end{array}$ & $\begin{array}{ll}\begin{array}{l}\text { Source } \\
\text { variation }\end{array} & \text { of }\end{array}$ & $\begin{array}{l}\text { Sum of } \\
\text { Square (SS) }\end{array}$ & $\begin{array}{lr}\text { Degree of } \\
\text { Freedom (DF) }\end{array}$ & $\begin{array}{l}\text { Square } \\
\text { (MS) }\end{array}$ & Mean & $\begin{array}{l}\text { Value } \\
\mathrm{F}\end{array}$ & Sig. \\
\hline \multirow{6}{*}{$\begin{array}{l}\text { Awareness of } \\
\text { risk nature }\end{array}$} & Sex & 1.705 & 1 & & 1.705 & 30.319 & $0.000^{*}$ \\
\hline & $\begin{array}{l}\text { Academic } \\
\text { Experience }\end{array}$ & 0.008 & 2 & & 0.004 & 0.074 & 0.928 \\
\hline & $\begin{array}{l}\text { Academic } \\
\text { Rank }\end{array}$ & 0.085 & 2 & & .042 & 0.755 & 0.472 \\
\hline & Faculty & 0.154 & 1 & & 0.154 & 2.745 & 0.101 \\
\hline & The mistake & 5.512 & 98 & & 0.056 & & \\
\hline & Total & 212.640 & 105 & & & & \\
\hline \multirow[t]{5}{*}{ Facing risk } & Sex & 0.0003 & 1 & & 0.0003 & 0.004 & 0.948 \\
\hline & $\begin{array}{l}\text { Academic } \\
\text { Experience }\end{array}$ & 0.556 & 2 & & 0.278 & 2.876 & 0.061 \\
\hline & $\begin{array}{l}\text { Academic } \\
\text { Rank }\end{array}$ & 0.334 & 2 & & 0.167 & 1.731 & 0.182 \\
\hline & Faculty & 0.374 & 1 & & 0.374 & 3.872 & 0.052 \\
\hline & The mistake & 9.468 & 98 & & 0.097 & & \\
\hline
\end{tabular}




\begin{tabular}{|c|c|c|c|c|c|c|}
\hline \multirow{3}{*}{$\begin{array}{l}\text { Diagnosing } \\
\text { risk }\end{array}$} & Total & 247.560 & 105 & & & \\
\hline & Sex & 0.181 & 1 & 0.181 & 0.339 & 0.562 \\
\hline & $\begin{array}{l}\text { Academic } \\
\text { Experience }\end{array}$ & 0.532 & 2 & 0.266 & 0.499 & 0.609 \\
\hline \multirow{10}{*}{$\begin{array}{l}\text { Taking } \\
\text { decisions } \\
\text { about risk }\end{array}$} & $\begin{array}{l}\text { Academic } \\
\text { Rank }\end{array}$ & 0.598 & 2 & 0.299 & 0.561 & 0.572 \\
\hline & Faculty & 0.113 & 1 & 0.113 & 0.212 & 0.646 \\
\hline & The mistake & 52.243 & 98 & 0.533 & & \\
\hline & Total & 1529.556 & 105 & & & \\
\hline & Sex & 0.102 & 1 & 0.102 & 0.233 & 0.630 \\
\hline & $\begin{array}{l}\text { Academic } \\
\text { Experience }\end{array}$ & 0.243 & 2 & 0.122 & 0.278 & 0.758 \\
\hline & $\begin{array}{l}\text { Academic } \\
\text { Rank }\end{array}$ & 0.508 & 2 & 0.254 & 0.580 & 0.562 \\
\hline & Faculty & 0.205 & 1 & 0.205 & 0.469 & 0.495 \\
\hline & The mistake & 42.899 & 98 & 0.438 & & \\
\hline & Total & 1562.796 & 105 & & & \\
\hline \multirow{6}{*}{$\begin{array}{l}\text { "risk } \\
\text { assessment } \\
\text { and review" }\end{array}$} & Sex & 0.010 & 1 & 0.010 & 0.017 & 0.897 \\
\hline & $\begin{array}{l}\text { Academic } \\
\text { Experience }\end{array}$ & 0.095 & 2 & 0.047 & 0.078 & 0.925 \\
\hline & $\begin{array}{l}\text { Academic } \\
\text { Rank }\end{array}$ & 0.319 & 2 & 0.159 & 0.263 & 0.769 \\
\hline & Faculty & 1.364 & 1 & 1.364 & 2.254 & 0.136 \\
\hline & The mistake & 59.311 & 98 & 0.605 & & \\
\hline & Total & 1444.528 & 105 & & & \\
\hline \multirow[t]{6}{*}{ Faculty } & Sex & 0.066 & 1 & 0.066 & 0.313 & 0.577 \\
\hline & $\begin{array}{l}\text { Academic } \\
\text { Experience }\end{array}$ & 0.110 & 2 & 0.055 & 0.262 & 0.770 \\
\hline & $\begin{array}{l}\text { Academic } \\
\text { Rank }\end{array}$ & 0.164 & 2 & 0.082 & 0.391 & 0.678 \\
\hline & Faculty & 0.189 & 1 & 0.189 & 0.903 & 0.344 \\
\hline & The mistake & 20.560 & 98 & 0.210 & & \\
\hline & Total & 853.506 & 105 & & & \\
\hline
\end{tabular}

The data presented in Table (4) indicate that at the macro level there are no statistically significant differences at the level of significance $(\alpha \leq 0.05)$ in the reality of risk management practice in private Jordanian universities from the viewpoint of faculty members in it due to the variables (gender, academic experience, Academic rank, and college type). As for the domains level, the results showed that there are statistically significant differences in the domain of "awareness of the nature of risks" due to the gender variable and when extracting the arithmetic averages it was found that the average of male estimates (1.44) and the average of female estimates (1.07) indicating that the differences were in favor of males.

With regard to the gender variable, it was found that there are no statistically significant differences in the arithmetic averages in the total score for the reality of risk management in private Jordanian universities. This is due to the fact that most of the faculty members in these universities live within a similar environment in their universities and are subject to similar administrative conditions. Consequently, their points of view are similar. In addition, males are more aware of the dangers than females because of the nature of sex. 
As for the variable of experience, it was found that there were no statistically significant differences in mathematical averages in the total score for the reality of risk management. This result may be attributed to the fact that the faculty members are subject to organizational and administrative conditions within private universities and are subject to the same responsibilities and duties regardless of their varying experiences. Therefore, their view of the reality of risk management planning is the same regardless of their level of expertise. This finding is consistent with Al-Zubaidi's study (2014). However, it differed from the study of Al-Malkafi (2019).

With regard to the variable of the academic ranks, it was found that there were no statistically significant differences in the arithmetic averages. Thismight be attributed to the members of the study sample regardless of their scientific ranks. They understand the importance of risk management in their universities and the associated dimensions. This is consistent with the study of Al-Zubaidi(2014).

As for the variable of the college type, it was found that there were no statistically significant differences in the arithmetic averages in the total score for the reality of risk management in private Jordanian universities. This might be attributed to the fact that the sample members are faculty members in private Jordanian universities. They practice similar work in terms of teaching and administrative work, and within a similar organizational climate in the scientific and humanities faculties in private Jordanian universities. Therefore, their view of the reality of risk management is similar regardless of the type of faculty to which they belong. This finding is consistent with thestudyofHelsloot, \& Jong, (2006).Based on the results discussed above, the study recommends; first, Private Jordanian universities should hold training courses for their workers on risk management planning. Second, they should coordinate with the concerned agencies in the country when drawing up plans for managing risks. Finally, comparative studies should be conducted by researchers on the reality of risk management in public and private universities in Jordan.

\section{References}

Abdel-Aal, Tariq (2007). Risk Management Individuals - Administrations - Companies - Banks (, University House, Alexandria., 1st floor, 146.

Adam, C. \&Kristonis, W. (2012). An analysis of secondary schools risk management prep redness. National journal for publishing and mentoring doctoral students' research, 1(1), 20-35.

Al-Ameri, Muhammad Ali (2018). Governance and political risk: a theoretical knowledge framework with an adaptation of a global scale for the purposes of the governance of Arab universities.Journal of the Association of Arab Universities for Research in Higher Education, 2(38), 37-52.

Ali, Karim (2016). Crisis management for heads of academic departments. Journal of the Basic Education College, 22(94), 724-7705.

Al-Najjar, Ghassan Muhammad (2017). The impact of risk management among entrepreneurial entrepreneurs on achieving the competitive advantage of their projects, case study: Incubator projects for business and technology at the Islamic University. Unpublished Master Thesis, Islamic University - Gaza.

Al-Zubaidi, Rabab Abdel-Wahab (2014). Risk Management in University Colleges, University of Baghdad from the viewpoint of department heads and teaching staff, unpublished Master Thesis, University of Baghdad, Iraq.

Anzi, Saad; Al-Dulaimi, Ark (2015). Impact of risk management and its benefits on organizations: a theoretical and analytical approach. Anbar University Journal for Economic and Administrative Sciences, 7(13), 969-958.

Booker, L. (2014). Crisis Management: Changing Time for Colleges, Journal of College Admission, 4(2),17-23.

Helsloot, I. \& Jong, W.(2006). Risk Management in Higher Education and Research in the Netherlands, Journal of Contingencies and Crisis Management, 14(3).https://doi.org/10.1111/j.1468-5973.2006.00490.x

Megginson, W. \&Bortolotti, B. D'souza, J. Fantini, M, L(2000). Privatization and the sources of performance improvement in the global telecommunications industry. Telecommunication Policy, 26(5-6), 243-268.https://doi.org/10.1016/S0308-5961(02)00013-7

Muzaffar, Duha Basil (2016). The Impact of Leadership Styles on Crisis Management by Centering Strategic Planning: Field Research at the Ministry of Electricity headquarters. Journal of Economic and Administrative Sciences, 22(92), 159-196.

Wilkins, I. (2010). An analysis of program risks management leading towards the development of a model for secondary school, Dissertation Abstract international, 8(58), 32-48. 